デシタル計算機を利用して, 比抵抗法の結果解析に新生面を開 レていてうとする狙いのもとに, 1963 年から, 標題に関連する 比抵抗多層問題の研究を進めて来たが, 開発されたプログラムは, 組込李れている計算の方法およびデジタル計算機の能力によつて, それぞれその使用限界がある。乙れを見い出すのには，さらに， かなりの長年月を要するものと思われる。

\section{1. 方法とその応用}

取り扱つた問題は，物理数学的に表現すると，(1)境界值問題 と (2)逆境界值問題とに跨がつているが, 計算の方法はいずれも 簡単なるのばかりである。

（1）の計算，すなわち，標集曲線の計算で試みた方法は，

(a) 核関数の多項式展開, (b) 核関数の直交多項式展開, (c) 核関数の多項式による最小自乗近似（これは（b) と全く同じ結果 をるたらすが，計算の仕方が本質的に異なる），（d）核関数の級 数展開などであり；(2)の方法，すなわち，見掛比抵抗一電極間 曲線（以下乙れをRS 曲線と書く。R S は Resistivity Sounding の略）の数值解析に関して行なつた計算方法は，（A）RS 曲線の 多項式近似，(B) RS 曲線の多項式による最小自乗近似などであ る。

（1）の場合の計算目的は，R S 曲線のカーブマッチングによる 解析のための多䊬標準曲線群を作るととであるが，その応用とし て, (a) 標準曲線の特性, (b) 電極配置飞よる標準曲線の相違点 (c) 2 層標準曲線法に上る実測 R S 曲線の解析結果の照合，(d) $n$ 層曲線と $n+1$ 層曲線との相互関係，(e) 比抵抗分布が深さの 関数として与えられるとをの RS 曲線の近似計算, (f) R S 曲線
の分解能などに関する研究が含まれており、（2）の方法は実測 $\mathrm{RS}$ 曲線から，直接飞， $\rho_{1}, \rho_{2}, \cdots \cdots ; h_{1}, h_{2} \cdots \cdots$ を 算出するととであるが, (1) の (f)の研究にる使える。

$$
\text { 2. プログラム }
$$

7層までの多層構造に対するWenner と Schl umberger の標準 曲線まよび見掛比坻抗曲線を計算するプログラムを第 1 表に提出 する。

$\mathrm{NA} ：$ 電極間隔の組数

$\mathrm{N}$ : 近似多項式の次数

$A_{1}, A_{2}, A_{N A}: N A$ 組の電極間隔 (Wenner)

$\mathrm{AM}_{1}, \mathrm{AN}_{1}, \cdots, \mathrm{AM}_{\mathrm{NA}}, \mathrm{AN}_{\mathrm{NA}}: \mathrm{NA}$ 組の電極間隔（Schlumberger ),

LAYER：地層の数,

RHO $[1], \cdots$, RHO $[$ LAYER $]$ ：LAYER 組の比抵抗，

AH〔 1]，…AH〔LAYER-1〕：LAYER-1組の地層境界面深 度

とするとを, 入カデーターは, $\mathrm{NA}, \mathrm{N}, \mathrm{A}_{1}, \mathrm{~A}_{2}, \cdots, \mathrm{A}_{\mathrm{NA}}$, $\left.\mathrm{AM}_{1}, \mathrm{AN}_{1}, \mathrm{AM}_{2}, \mathrm{AN}_{2}, \cdots, \mathrm{AM}_{\mathrm{NA}}, \mathrm{AN}_{\mathrm{NA}}, \mathrm{LAYER}, \mathrm{RHO} 1\right]$, RHO $[2], \cdots, R H O[L A Y E R], A H[1], \operatorname{AH}\{2], \cdots, \operatorname{AH}[\mathrm{LA}$ YER-1]，O，の順番でカードにパンチされる。最後のOはデー ターのつをととを示す整数で，乙れを読み込むと計算は終了す るととになる。しいくつかのモデルについて，RS曲線を計算 しょうとするとをとは, ANNA とOとの間に, 順序よく,LAYER $\cdots$, AH(LAYER-1)をいくうす並べてパンチすればよい。計算の゙終 りのため, 最後に○をパンチする。

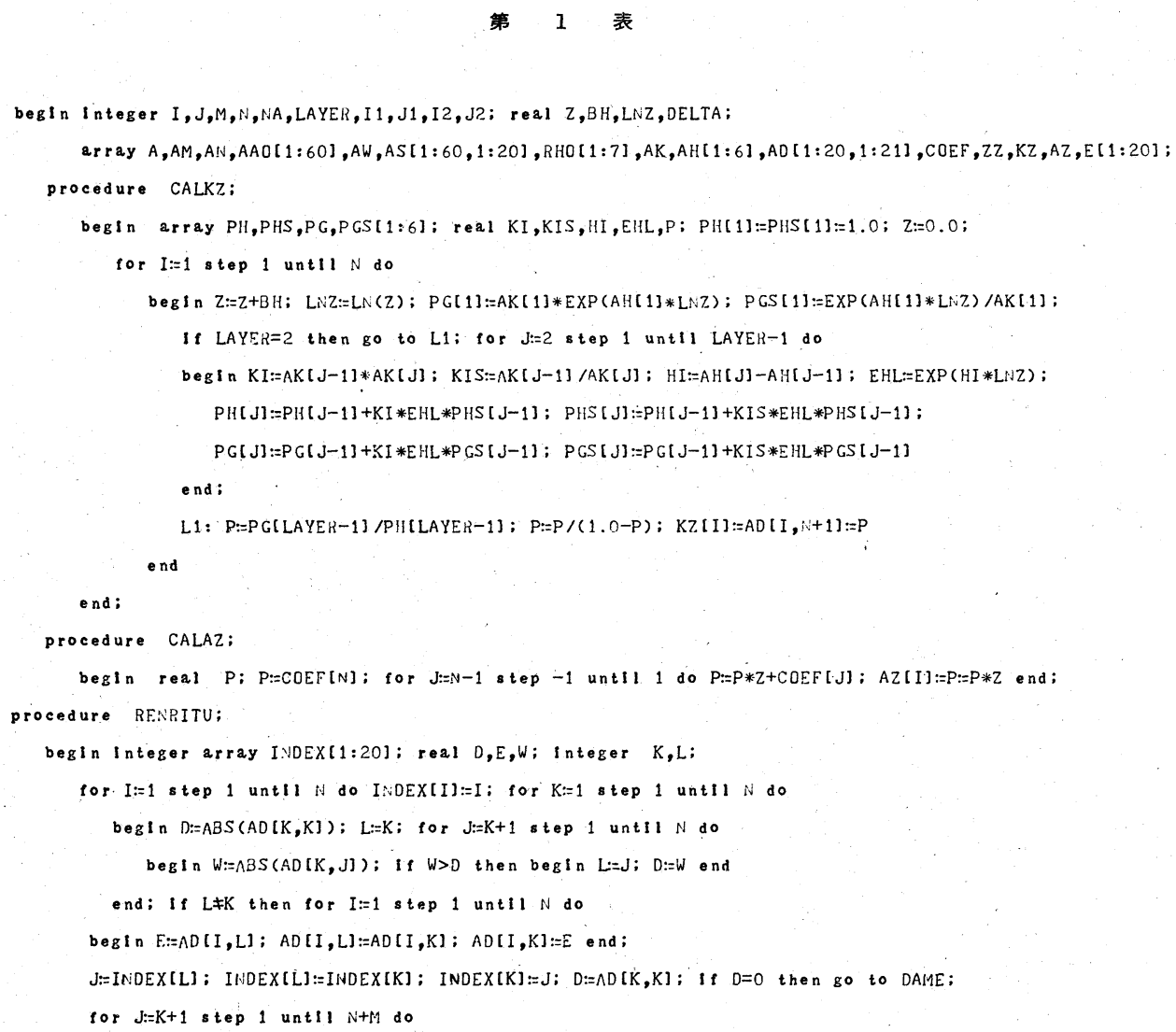


begin $E:=A D[K, J]:=A D[K, J] / D$; for $I:=1$ step 1 untll $N$ do if $I \neq K$ then $A D[I, J]:=A D[I, J]-E * A D[I, K]$ end end;

ORDER: for $I:=1$ step 1 untll $N$ do if $I \neq I N D E X[I]$ then begin $L:=I$;

CONTIHUE: if $I \neq I N D E X[L]$ then begin $L:=L+1 ;$ go to CONTINUE end else

begin for J:: +1 step 1 untll $N+M$ do

begln $W:=A D[I, J] ; A D[I, J]:=A D[L, J] ; A D[L, J]:=W$ end; INDEX[L]:=INDEX[I]

end; end; go to END;

DAME: PRINT('DAMEbDESU.K="); $\operatorname{PRINT}(3, \mathrm{~K}) ; \operatorname{CRLF}(5) ;$ if $K=N$ then go to ORDER;

END:

end :

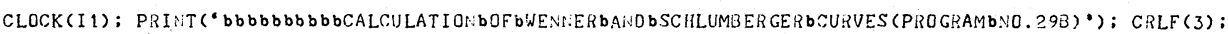

$\operatorname{READ}(N A, N)$ :

for $I:=1$ step 1 untll NA do

begin real $T, T T, F J, F F J ; R E A D(T) ; A[I]:=T ; T T:=T * T$;

for $J:=1$ step 1 untll $N$ do

begin FJ:=FLOAT(J); FFJ:=FJ*FJ; AW[I, J]:=T*(4.O/SQRT(4.0*FFJ+TT)-2.0/SQRT(FFJ+TT)) end

end

for I:=1 step 1 unttl NA do

begtn real $T, U, T T, U U, F J, F F J ; R E A D(T, U) ; A M[I]:=T ; A U:[I]:=U ; T T:=T * T ; U U:=U * U$;

for $J:=1$ step 1 until $N$ do

begIn FJ::FLOAT(J); FFJ:=FJ*FJ; ASII, J]:=(2.0/S2RT(4.0*FFJ+TT)-2.0/SQRT (4.0*FF J+UU))*T*U/(U-T) end end:

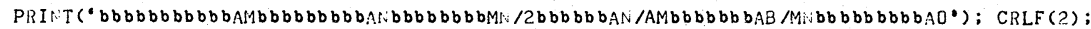

for $I:=1$ step 1 unttl NA do

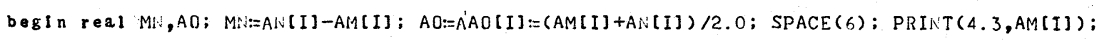

PRINT(4.3,AN(I]): PRINT(4.3,MN/2.0); PRINT(1.6,AN[I]/AM[I]); PRINT(2.6,2.0*AO/MN); PRINT(4.4,AO); CRLF(1)

end; $\operatorname{CRLF}(2)$ :

$\operatorname{CLOCK}(J 1) ; \operatorname{PRIVT}(4, J 1-I 1) ; \operatorname{CRLF}(2)$;

START: $\operatorname{CLOCK}(12)$ ) READ(LAYER); is LAYER=0 then go to END;

tor I:=1 step 1 untll LAYER do READ(RHO[I]);

for $I:=1$ step 1 unt!l LAYER-1 do AK[I]:=(RHD [I+1]-RHO[I])/(RHO[I+1]+RHO[I]):

for I:=1 step 1 untll LAYER-1 do READ(AH[I]);

PRINT( ('bbbbbbbbbbIbbbbbbbbRHObbbbbbbbbbbKbbbbbbbbbbbbH'); CRLF(2);

for $I:=1$ s tep 1 until LAYER-1 do

begin SPACE(7); PRINT(2,I); PRINT(4.7,RHO(I)); PRINT(1.7,AK[I]); PRINT(4.7,AH(I)); CRLF(1) end;

SPACE(7); PRINT(2,LAYER); PRINT(4.7, RHO[LAYER]); CRLF(2);

BH:=1.0/FLOAT $(N) ; Z:=0.0$; for I:=1 step \& unthl $N$ do

begin real FJ; $Z:=Z+B H ; Z Z[I]:=Z$; for $J:=1$ step 1 untll $N$ do

begIn FJ:=FLOAT(J); LNZ:=LN(Z); AD $[I, J]:=\operatorname{EXP}(F J * L N Z)$ end ;

end

CALKZ; M:=1; RENRITU:

tor $I:=1$ step 1 untti $N$ do $\operatorname{COEF}[I]:=A D[I, N+1]$;

$Z:=0$; for $I:=1$ step 1 untll $N$ do begin $Z:=Z+B H: C A L A Z$ ondifor $I:=1$ step 1 unttl $N$ do

beg In DELTA:=2.0*ABS(AZ(I)-KZ[I]): E[I]:=DELTA; ond:

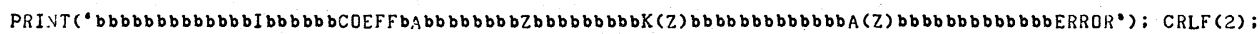

for $I:=1$ step 1 untll $N$ do

begin SPACE(10); $\operatorname{PRINT}(2, I) ; \operatorname{PRINT}(9, \operatorname{COEF}[I]) ; \operatorname{PRINT}(1.2, \mathrm{ZZ}[I]) ; \operatorname{PRINT}(9, \operatorname{KZ}[I]) ; \operatorname{PRINT}(9, \operatorname{AZ}[I])$;

PRINT(9,E[I]); CRLF(1) end; $\operatorname{CRLF}(2)$;

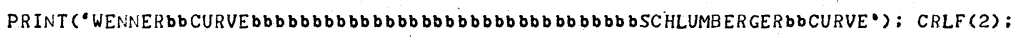

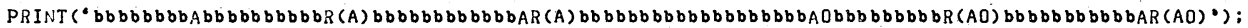

CRLF(2): sor I:=1 step 1 untll NA do

begin real $R S, R W$; $R W:=R S:=1.0$; for $J:=1$ step 1 untsl $N$ do

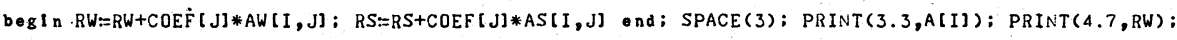

PRINT(5.7,RW*RHO(1]); $\operatorname{SPACE}(10) ; \operatorname{PRINT}(3.3, \operatorname{AAO}[1]) ; \operatorname{PRINT}(4.7, R S) ; \operatorname{PRINT}(5.7, R S * R H O[1]) ; \operatorname{CRLF}(1)$

ond; $\operatorname{CRLF}(2)$; $\operatorname{CLOCK}(\mathrm{J} 2)$; PRINT(4,J2-I2); $\operatorname{CRLF}(2)$; go to START; 
7 層以上のモデルについて計算したいとをは，たとえば，50 層の計算を試みるとをには, $\operatorname{RHO}[1: 50], \mathrm{AK}, \mathrm{AH}[1: 49]$, PH, PHS, PG, PGS $[1: 49]$ 亿直せばよい。

近似多項式の次数 $\mathrm{N}$ を 20 以上に取りたいとをは，たとえば， $\mathrm{N}$ を 50 にしたんとをには, $\mathrm{AW}, \mathrm{AS}\{1: 60,1: 50\}, \mathrm{AD}[1$ : $50,1: 51], \mathrm{COEF}, \mathrm{ZZ}, \mathrm{KZ}, \mathrm{AZ}, \mathrm{E}[1: 50], \operatorname{INDEX}[1:$ 50 とすればよん。乙のとさ，指定する $\mathrm{N}$ に応じて，数值の有効 桁数が増していかないと, 計算結果が意味を持たなくなる。

さらに，電極間隔を 60 組以上に増したいとをは，たとえば， 100 組にして計算しょうとするとをは，A，AM, A N , A A O 〔1:100\}とすればよん。

てらして、いくらでも計算を拡張するてとがでをるが，デシタ ル計算機にはおのずから番地に制限があるので，どの計算機でも らかなる計算でもできるとは限らない。

要するに，プログラムに組込まれている計算法の性質によつて 核関数がスムーズな曲線であるとき，精度の高い結果が得られ， また，乙のプログラムをもとにして，いろいろな組合せの入カデ ーターについても計算でさるようなプログラムを書を下すととが できよう。

\section{3-, 4-, 5- 層標準曲線}

よく知られている 2 層標準曲線において， $\rho_{1}<\rho_{2}$ のときの標 準曲線群を1で表わし； $\rho_{1}>\rho_{2}$ のとさの標準曲線群を 2 で表わ すと, 3-，4-，5層の標準曲線には， $2^{n-1}$ 個の特性曲線が存 在する（第 2 表）。ただし $n$ は地層の数を表わす。

第 2 表 特性曲線の種類

\begin{tabular}{|c|c|c|}
\hline 層 & 層 & 層 \\
\hline $1(1,1)$ & $\begin{array}{l}1(1,1,1) \\
2(1,1,2)\end{array}$ & $\begin{array}{l}1(1,1,1,1) \\
2(1,1,1,2) \\
3(1,1,2,1) \\
4(1,1,2,2)\end{array}$ \\
\hline $2(1,2)$ & $\begin{array}{l}3(1,2,1) \\
4(1,2,2)\end{array}$ & $\begin{array}{l}5(1,2,1,1) \\
6(1,2,1,2) \\
7(1,2,2,1) \\
8(1,2,2,2)\end{array}$ \\
\hline $3(2,1)$ & $\begin{array}{l}5(2,1,1) \\
6(2,1,2)\end{array}$ & $\begin{array}{r}9(2,1,1,1) \\
10(2,1,1,2) \\
11(2,1,2,1) \\
12(2,1,2,2)\end{array}$ \\
\hline $4(2,2)$ & $\begin{array}{l}7(2,2,1) \\
8(2,2,2)\end{array}$ & $\begin{array}{l}13(2,2,1,1) \\
14(2,2,1,2) \\
15(2,2,2,1) \\
16(2,2,2,2)\end{array}$ \\
\hline
\end{tabular}

第 1，2，3図に示した特性曲線は，実測 R S 曲線を解析する 際の基礎知識として役立つであろら。しかし， $\rho_{i}, h_{i}$ のとり方 次第では，多層曲線であつても，それょりる地層数の少ない場合 の曲線に漸移する傾向がある。このようなケースのR S 曲線の解 析は困難になるし，また解析結果の信頼性が失なわれてくる。

\section{4. 解 析 実 例}

私がとつている実測曲線の解析のやり方は, わが国でよく行な われている 2 層標準曲線法による解析結果を照合し, 試行によつ て実測曲線に合致する理論曲線を計算するてとである。

湘定値の中の不規則な值の取り扱いは，まだ確立されていない し，また，たとえ地下が成層をなしているときです，上に述べた ことによつて,そらして得られた結果は必ずしも唯一解を示さな いととがわかる。

第 4 図は大岳地熱地帯におらて選定した測線 L O ; 测点 S 15 におらで, Schlumberger 電極配置に対して得られた実測值を縦 軸に，L/2 を横軸にとつて $\log -\log$ 表示したるのである。図 において, $\mathrm{MN}=2 \mathrm{~m}, \mathrm{~L} / 2=5,7,10,15 \mathrm{~m}$ のとをの見掛比 抵抗值老白丸印; $\mathrm{MN}=5 \mathrm{~m}, \mathrm{~L} / 2=15,20,30,40,50 \mathrm{~m}$ のとをの值を黒丸印; $\mathrm{MN}=20 \mathrm{~m}, \mathrm{~L} / 2=50,70,100,150$, $200 \mathrm{~m}$ のとをの值を白丸印; $\mathrm{MN}=80 \mathrm{~m}, \mathrm{~L} / 2=200 ， 300$, $400 \mathrm{~m}$ のとあ值を黒丸印; $\mathrm{MN}=160 \mathrm{~m}, \mathrm{~L} / 2=400,500$, $600 ， 700 ， 800 ， 900 ， 1000 \mathrm{~m}$ のときの值を白丸印で表わし てんる。

実線で書かれた曲線は第 4 図の上部に示している比抵抗層に対 する理論曲線である。 $\mathrm{L} / 2=150 ， 200 ， 400 ， 800 ， 900$ ， $1000 \mathrm{~m}$ のとをの実測值 (白丸印) および $\mathrm{L} / 2=300,400 \mathrm{~m} の$ とをの実測值（黒丸印）は計算值とかけはなれているが，電極接

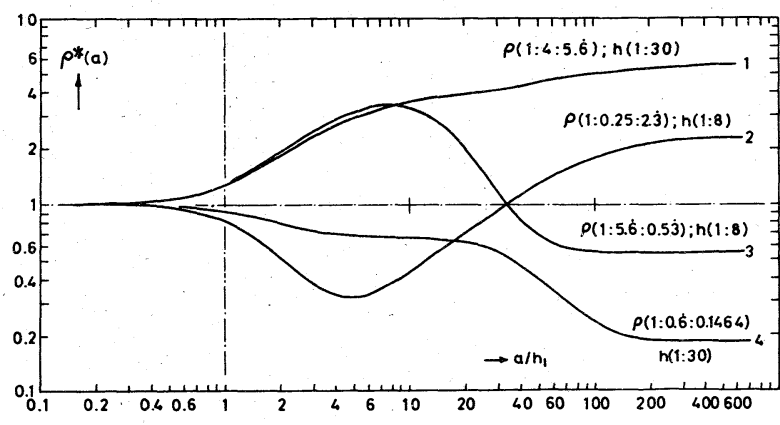

第1図 Four types of standard resistivity curves for three 1 aye red models

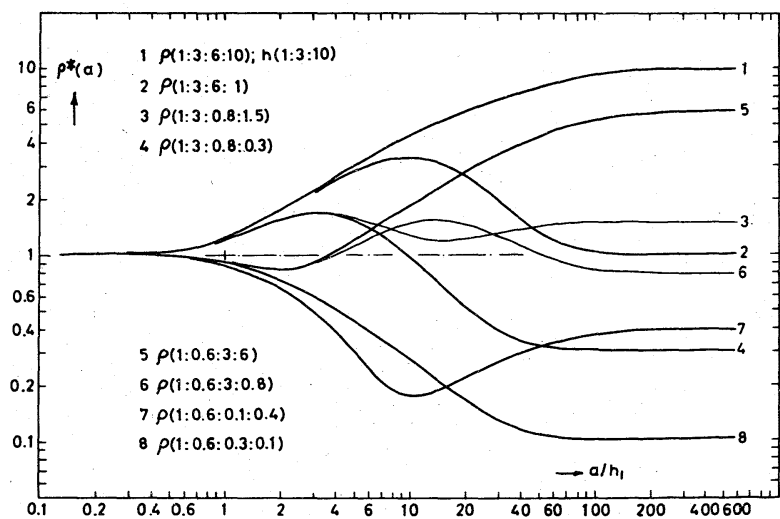

第2図 Eight types of standard resistivity curves of four ayered models

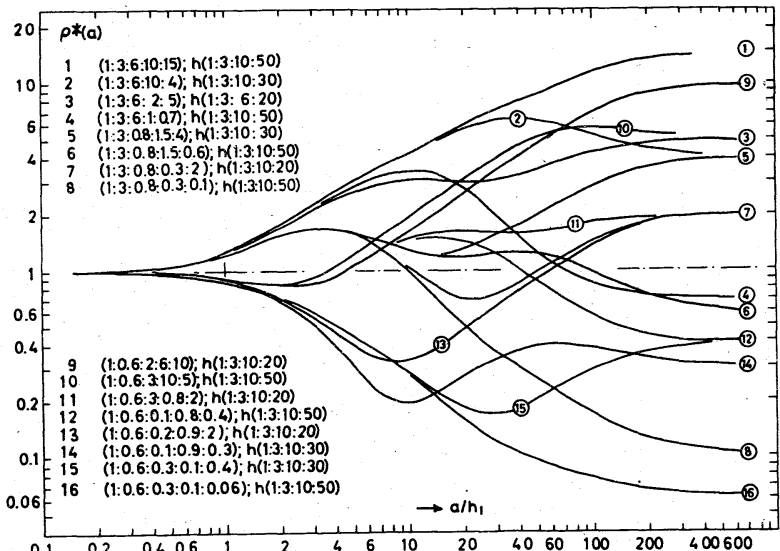

第3図 Sixteen types of standard resistivity curves for five 1 ayered models

RESISTIVITY LAYER

\begin{tabular}{l|l|l|l}
\hline 200 & 1200 & 20 & 150 Ohm-m \\
\hline 3 & 13 & $480 \mathrm{~m}$
\end{tabular}

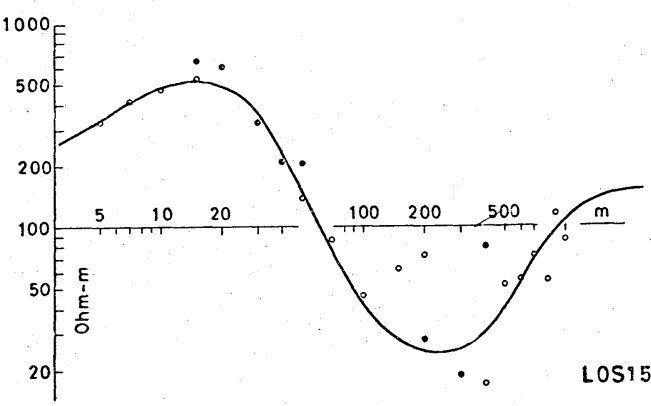

第4図 The result of interpreting the field curve obtained at $\operatorname{LOS} 15$ 
地点の地形や地質条件を考慮すると, これらは地表地形や地表近 くの地質の影響であると判定するととがでをる。てのような曲線 は大岳地熱地帯の典型曲線であつて, 比抵抗 $20 \Omega \cdot m$, 厚さ $467 \mathrm{~m}$ で与えられる第 3 比抵抗層壮安山岩の変質帯に相当し, レ ザーバーと考えるととがでるる。

てのような解析結果を測線についてをとめ，あるいは全測線に ついてまとめると，地熱地带の比抵抗ブロックダイアグラムがで きがり，それが比抵抗法の結果解析に上つて与えられる1つの 地下情報になる。

\section{5. 講 演 の内容}

シンポジゥムの前半におらては, 私の愛着が最も強く, また生 涯棄て切れないであろら研究のテーマである比抵抗多層問題の追 求に焦点を絞り，その概要を報告し，その後半では，ての研究の 実際面への応用とその結果の反省などをいくつかの実例を挙げて 今までの研究を振り返つてみたい。

\section{$\mathbf{A}^{\prime}-2$ アナログ計算機による結果解析}

京都大学工学部 吉 住 永三郎

\section{1. 緒言}

金属鉱床の電気探査の結果解釈は一般に困難である。理論的に はポテンシャル論の逆境界値問題になり，簡単な例題の場合でも 相当に難解である。この報告では, 当研究室で研究開発したアナ ロク計算機を用いる結果解釈法について説明する。

アナロク計算機（アナロクシミュレータ）の発想は昭和 29 年 飞さかの深り，無限媒質を有限な抵抗体の集合で表現するといら 考え方で，らわゆる「固定抵抗網」之呼称して，抵抗を網目状に 組み合わせた抵抗網を試作した。当時は，乙の固定抵抗網による 実験結果が果して理論的に解析された結果とどの程度相似するか というととが大きな問題であつた。現在「アナロク計算機」と呼 称する装置を試作し，アナログ計算機にょる結果解釈法を一応確 立した。

\section{2. 地形の影}

地形が電気探査の測定結果に及深す影嚮は想像以上に大をい。 ての報告では土木関係で測定した $2 つ の$ 探査結果につんて, 地形
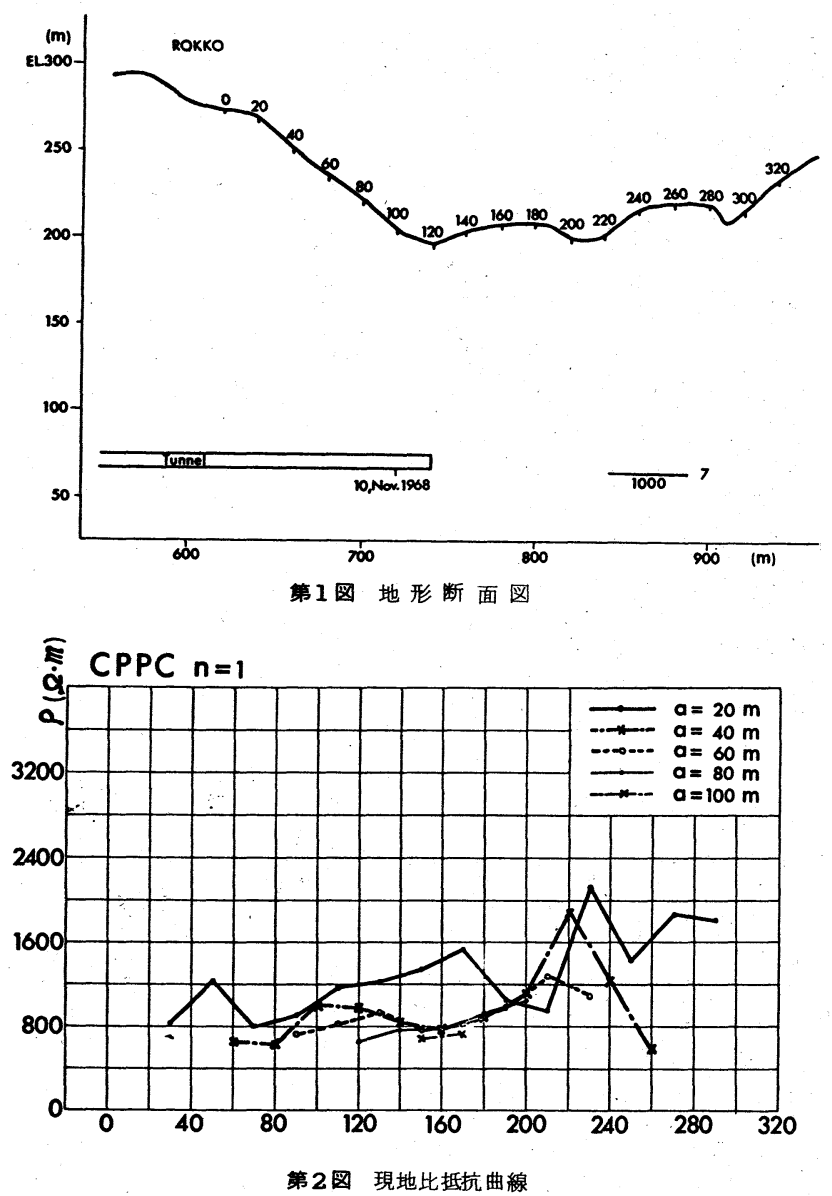

$542<10>$
断面図と現地での測定結果とアナロク計算機による地形のみの解 析結果とをそれぞれ示す。

\section{$2 \cdot 1$ 山陽新幹線六甲トンネルの例}

山陽新幹線六甲トンネルは鹿島建設侏式会社で施工した工事で あるが, 乙の探査は昭和 43 年 11 月に, 杣谷川下部における破 碎帯の存在を探査する目的で実施されたるのである。

第 1 図は探査地区の 1 つの測線の地形断面図で, 地形とともに トンネルの位置が示されている。第 2 図は CPPC電極配置におい て, 電極間隔 $a$ を $20 \mathrm{~m}, 40 \mathrm{~m}, 60 \mathrm{~m}, 80 \mathrm{~m}$ おび $100 \mathrm{~m}$ とした 場合の現地での比抵抗の測定結果である。横軸は測点番号で第 1 困の測点番号と対応し，測点間隔は $20 \mathrm{~m}$ である。

第 3 図はアナログ計算機によつて解析された地形均質曲線で, 第 2 図の CPPC 電極配置の場合に対応し，第 1 図の地形のみにょ る影響で地下構造を均質な媒質と仮定した場合の結果である。

第 2 図と第 3 図を比較すると, 対応する曲線の傾向はよく一致 しており, 電極間隔 $a$ が $20 \mathrm{~m}$ におしては地表近くの地下構造の 影響が現われており，地形と表土屏による大をな異常が示されて レる。

\section{2 関西電力下小鳥ダムの例}

関西電力下小鳥ダムは株式会社新日本技術コンサルタントの設 計になるもので，乙の探査は昭和 43 年 10 月に，ロックフィル ダムのダム堤体に用いるコア材を探査する目的で実施されたるの である。

第 4 図は探査地区の 1 つの測線の地形断面図である。第 5 図は $\mathrm{CPPC}$ 電極配置々おらて, 電極間隔 $a$ を $10 \mathrm{~m}, 20 \mathrm{~m}, 40 \mathrm{~m}$ およ び $80 \mathrm{~m}$ とした場合の現地での比抵抗の測定結果である。横軸は 測点番号で第 4 図の測点番号と対応し，測点間隔は $10 \mathrm{~m}$ である。

第 6 図はアナロク計算機によつて解析された地形均質曲線で, 第 5 図の CPPC電極配置の場合に対応し, 第 4 図の地形のみによ る影響で地下構造は均質な媒質と仮定した場合の結果である。

第 5 図と第 6 図を比較すると, 地形の影咺と地表近くの地下構

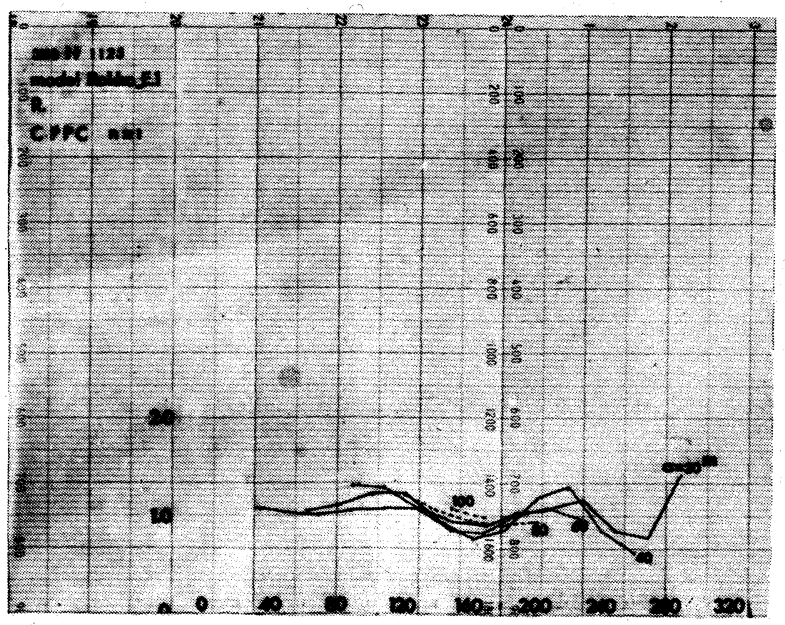

第3図 計算機地形均質曲線 